\section{Measles: the legacy of low vaccine coverage}

\author{
Mary E Ramsay
}

Measles is among the most infectious diseases of humans. Prior to the introduction of vaccination, virtually every child in the UK caught measles during two-yearly epidemics that each involved up to 700000 reported cases. The illness presents with fever, coryza, cough and conjunctivitis before progressing to the classic rash after 2-4 days. ${ }^{1}$ Complications are more common in the very young and in adults and include otitis media, pneumonia, diarrhoea, keratitis and encephalitis. Although measles still kills around 150000 children per year worldwide, in industrialised countries, case-fatality ratios are low with around one death for every 2000-5000 reported cases. ${ }^{12}$ The infection is most serious for individuals who are immunosuppressed, who may experience diffuse progressive pneumonitis or a delayed form of encephalitis, both associated with a high risk of death. For example, between 1974 and 1984, nearly one-third of deaths in British children in remission from leukaemia were measles related. ${ }^{3}$ The WHO aims to achieve measles elimination in at least five WHO regions by 2020, with the elimination target for the European region set at 2015 . $^{4}$

In the UK, measles vaccine was first introduced in 1968 for children in the second year of life. Although a single dose of measles vaccine provides between 90 and $95 \%$ protection, ${ }^{5-7}$ coverage remained low and measles continued to cause regular epidemics right up until the late 1980s. In 1988 , the year that measles-mumps-rubella (MMR) vaccine was introduced, around 86000 cases and 16 deaths were reported in England and Wales. ${ }^{8}$ Following the introduction of MMR, coverage improved to $92 \%$ and was sustained at this high level throughout the early 1990s. In November 1994 , to prevent a predicted epidemic of measles amongst older children, combined measles-rubella vaccine was offered to all school children aged 5-16 years in a national vaccination campaign. ${ }^{9}$ Coverage of $92 \%$ was achieved in the campaign, and endemic transmission of measles was interrupted. ${ }^{10}$ In 1996, a second dose of MMR

Correspondence to Dr Mary E Ramsay, Department of Immunisation, Hepatitis and Blood Safety, Public Health England, 61 Colindale Avenue, London NW9 5EQ, UK; Mary.ramsay@phe.gov.uk was added to the routine vaccination schedule at around 4 years of age. After a second dose of measles containing vaccine, around $99 \%$ of children are protected. $^{11-15}$

In 1998, a single research group published a small case series of children with autism $^{16}$ and attracted substantial publicity in the mainstream media suggesting a link with MMR. Despite good scientific evidence against such an association, ${ }^{17} 18$ adverse media coverage was sustained over the next few years. Analysis suggested that the coverage was unbalanced and showed disproportionate interest in the potential side effects of MMR. ${ }^{19}$ One of the factors contributing to the lack of balance was that the story was largely covered by news journalists rather than health or science correspondents. The impact of the adverse publicity was monitored through surveillance of vaccine coverage and regular survey of parental knowledge and attitudes. ${ }^{20}$ By around 2001, safety concerns had reached their highest level with $24 \%$ of parents believing that MMR vaccine was a greater risk than the diseases it protects against. ${ }^{21} \mathrm{By}$ 2003-2004, MMR coverage in 2-year-old children fell to just below $80 \%$ in England, with lowest levels in London. ${ }^{22}$ In the same year, coverage in Wales was little better at $82.4 \%$, although coverage in Scotland and Northern Ireland remained high at $88.4 \%$ and $88.1 \%$, respectively. ${ }^{21}$

Despite the occurrence of occasional outbreaks, caused by limited secondary spread from imported cases, measles remained eliminated in England until $2005 .^{23}$ Sustaining measles elimination, however, requires a very high immunity level. Early mathematical models estimated that the herd immunity threshold for measles in industrialised countries is $91 \%$ to $94 \% .^{24}$ Later, modelling in the UK suggested that higher levels of susceptibility can be tolerated in preschool (around 15\%) and primary school age children (around 10\%), due to more limited numbers of contacts in these age groups. By secondary school age, however, a target of $95 \%$ immunity is required to sustain elimination. ${ }^{25}$

During 2006-2007, measles transmission became re-established. ${ }^{26}$ and large outbreaks of measles were reported in populations with low coverage, most notably the Orthodox Jewish population in London and Irish travelling communities across England. In 2008, historic coverage data were used to estimate the future control of measles; this suggested that most of London was already above the threshold required to sustain measles transmission and that an epidemic of up to 100000 cases of measles could occur. $^{27}$ This led the Chief Medical Office to announce a national catch-up campaign to offer MMR to any individuals under 18 years of age. ${ }^{28}$ The impact of this programme on coverage in older children is unclear, but cases of measles declined in late 2009 and remained low in 2010.

By 2010, the attitudinal tracking showed that confidence of parents had increased. ${ }^{29}$ with only $8 \%$ believing that MMR vaccine posed a greater risk than the diseases it protects. Efforts to increase MMR coverage in preschool children have also been increasingly successful, particularly in the London area. Quarterly data on MMR coverage at 2 and at 5 years of age were last published for the quarter October-December 2012. By 24 months, 92.4\% of English children had received their first dose of the MMR vaccine and by the age of 5 years, the proportion was $94.1 \%$, the highest level ever recorded. $^{30}$ For London, $87.1 \%$ of 2 -year-olds and $90.9 \%$ of 5 -year-olds have had at least one dose of vaccine.

Despite this improvement in coverage, measles cases increased in 2011, initially in association with a much larger epidemic in France. ${ }^{31}$ Monthly numbers of confirmed cases have remained high ever since, and a total of 1920 cases were confirmed in England in 2012, the highest number since 1994. In April 2013, a large outbreak was reported from Wales, with 693 cases in the Swansea area alone. ${ }^{32}$ In England, 1168 cases were confirmed, between January and May 2013 (http:// www.hpa.org.uk/hpr/archives/2013/news/ 2813.htm\#msls) but the most notable change was a shift in age distribution, with the highest number of cases in 10 14-year-olds. Teenagers were also the focus in Wales, ${ }^{33}$ because these cohorts were most affected by the decline in coverage-which reached the lowest level for 2-year-olds in 2003/04 and in 5 -year-olds in 2006/07 (figure 1). These children were born between April 2001 and March 2002 and would have started to enter secondary school in September 2012. The most likely reason therefore for the increase in cases in 2013 is that sustained historic low coverage has led to the accumulation of sufficient measles 


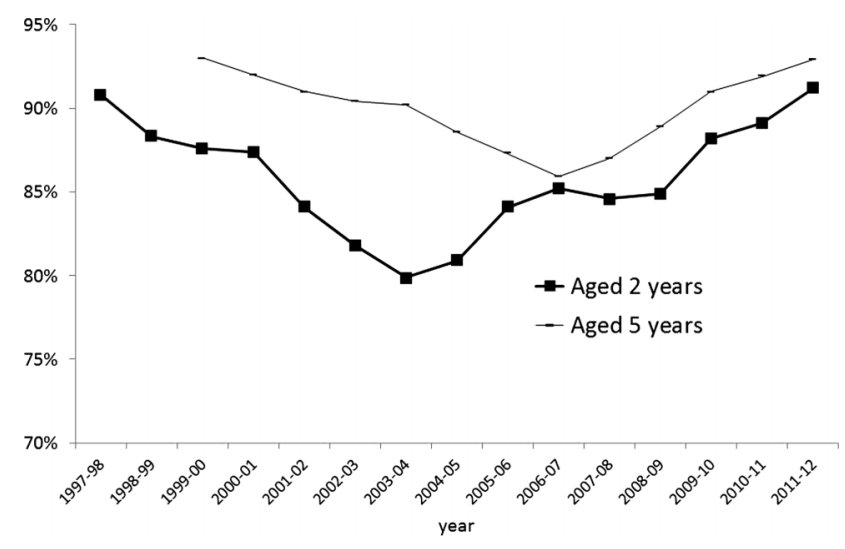

Figure 1 Coverage of first-dose MMR in England from 1997-98 to 2011-12.

susceptibles to allow transmission in the secondary school environment. The higher potential for transmission in secondary schools has also been demonstrated by outbreaks in the north-east and north-west, although younger children in known low coverage groups still feature in other parts of the country.

Paediatricians need to be aware of measles and promptly report cases to the local health protection teams based on Public Health England (PHE) Centres (https://www.gov. uk/government/publications/phe-centreaddresses-and-phone-numbers). When a case of suspected measles is reported and/or notified to the local health protection unit, an oral fluid kit is sent to the case or to the parent or general practitioner of the case. Samples are taken and returned to the PHE Virus Reference Department, where they are tested for antimeasles IgM and IgG. Oral fluid offers an additional advantage over serology because the sample can also be used for measles RNA detection, particularly for cases sampled within 3 days of rash onset that may be negative for antimeasles IgM. Measles RNA detection is also possible from respiratory samples, but sensitivity will depend on nature of the sample, timing and the method used. ${ }^{34}$ For accurate surveillance of measles, an oral fluid sample should always be arranged with the local health protection team, in addition to any local testing. Paediatricians also have an important role to play in protecting vulnerable children, such as those with leukaemia, cancer or other immune deficiency disorders, by ensuring that they are as up to date as possible for their own MMR vaccination, that their family are fully immunised and that their own immune status is established. The latter will facilitate a proper risk assessment of the child in the face of exposure to measles.

In response to the outbreak in Swansea, a vaccination campaign was initiated in patients and their families. ${ }^{35}$
Wales. $^{32}$ To prevent a similar epidemic in England, the Department of Health, PHE and NHS England have announced an MMR catch-up programme. The primary focus on the programme will be to target unvaccinated children aged $10-16$ years with the aim of preventing outbreaks in secondary schools and therefore onward transmission to young infants and other vulnerable groups. The strategy includes raising demand through targeted communications, identification of unvaccinated children through general practice and child health registers, and provision of vaccination in general practice or other settings such as schools. In support of this, the Royal College of Paediatric and Child Health has recently written to members urging them to use every opportunity to promote vaccination with their

\section{Competing interests None.}

Provenance and peer review Commissioned; internally peer reviewed.

Data sharing statement All data is public domain.

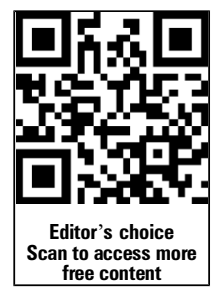

To cite Ramsay ME. Arch Dis Child 2013;98:752-754.

Received 17 May 2013

Revised 13 June 2013

Accepted 23 June 2013

Published Online First 29 July 2013

Arch Dis Child 2013;98:752-754.

doi:10.1136/archdischild-2013-304292

\section{REFERENCES}

1 Perry RT, Halsey NA. The clinical significance of measles: a review. J Infect Dis 2004;189(S1):S4-16.
2 Miller DL. Frequency of complications of measles, 1963. Report on a National Inquiry by the Public Health Laboratory Service in collaboration with the Society of Medical Officers of Health. Br Med J 1964;2:75-8.

3 Gray MM, Hann IM, Glass S, et al. Mortality and morbidity caused by measles in children with malignant disease attending four major treatment centres: a retrospective review. Br Med J (Clin Res Ed) 1987;295:19-22.

4 Anon. Global measles and rubella strategic plan: 2012-2020. World Health Organization, 2012. http://www.who.int/immunization/newsroom/ Measles_Rubella_StrategicPlan_2012_2020.pdf

5 Morse D, O'Shea M, Hamilton G, et al. Outbreak of measles in a teenage school population: the need to immunize susceptible adolescents. Epidemiol Infect 1994;113:355-65.

6 Calvert N, Cutts F, Miller E, et al. Measles in secondary school children: implications for vaccination policy. Commun Dis Rep CDR Rev 1994;4:R70-3.

7 Tohani VK, Kennedy FD. Vaccine efficacy in a measles immunisation programme. Commun Dis Rep CDR Rev 1992;2:R59-60.

8 Public Health England. Measles notifications and deaths in England and Wales, 1940-2008. http:// www.hpa.org.uk/web/HPAweb\&HPAwebStandard/ HPAweb_C/1195733835814 (accessed 23 July 2013).

9 Ramsay M, Gay N, Miller E, et al. The epidemiology of measles in England and Wales: rationale for the 1994 national vaccination campaign. Commun Dis Rep CDR Rev 1994:4:R141-6.

10 Gay N, Ramsay M, Cohen B, et al. The epidemiology of measles in England and Wales since the 1994 vaccination campaign. Commun Dis Rep CDR Rev 1997:7:R17-21.

11 Wichmann O, Hellenbrand W, Sagebiel D, et al. Large measles outbreak at a German public school, 2006. Pediatr Infect Dis J 2007;26:782-6.

12 Hennessey KA, Ion-Nedelcu N, Craciun MD, et al. Measles epidemic in Romania, 1996-1998: assessment of vaccine effectiveness by case-control and cohort studies. Am J Epidemiol 1999;150:1250-7.

13 Janaszek W, Gay NJ, Gut W. Measles vaccine efficacy during an epidemic in 1998 in the highly vaccinated population of Poland. Vaccine 2003;21:473-8.

14 Herceg A, Passaris I, Mead C. An outbreak of measles in a highly immunised population: immunisation status and vaccine efficacy. Aust $J$ Public Health 1994;18:249-52.

15 Vitek CR, Aduddell M, Brinton MJ, et al. Increased protections during a measles outbreak of children previously vaccinated with a second dose of measlesmumps-rubella vaccine. Pediatr Infect Dis J 1999;18:620-3.

16 Wakefield AJ, Murch SH, Anthony A, et al. Ileallymphoid-nodular hyperplasia, non-specific colitis, and pervasive developmental disorder in children. Lancet 1998;351:637-41.

17 Peltola H, Patja A, Leinikki P, et al. No evidence for measles, mumps, and rubella vaccine-associated inflammatory bowel disease or autism in a 14-year prospective study. Lancet 1998;351:1327-8.

18 Taylor B, Miller E, Farrington C, et al. MMR vaccine and autism: no epidemiological evidence for a causal association. Lancet 1999:353:2026-9.

19 Hargreaves I, Lewis J, Speers T. Towards a better map. Science, the public and the media. ESRC, 2003. http://www.esrc.ac.uk/ESRCInfoCentre/Images/ Mapdocfinal_tcm6-5505.pdf

20 Ramsay ME, Yarwood J, Lewis D, et al. Parental confidence in measles, mumps and rubella vaccine: evidence from vaccine coverage and attitudinal surveys. Br J Gen Pract 2002;52:912-16. 
21 Yarwood J, Noakes K, Kennedy D, et al. Tracking mothers attitudes to childhood immunisation 1991-2001. Vaccine 2005;23:5670-87.

22 Anon. NHS Immunisation Statistics, England: 2004-05. Health and Social Care Information Centre, 2005. https://catalogue.ic.nhs.uk/publications/ public-health/immunisation/nhs-immu-stat-eng-20042005/nhs-immu-stat-eng-2004-2005-rep.pdf

23 Ramsay ME, Jin L, White J, et al. The elimination of indigenous measles transmission in England and Wales. J Infect Dis 2003;187(S1): S198-207.

24 Anderson RM, May RM. Age-related changes in the rate of disease transmission: implications for the design of vaccination programmes. I Hyg (Lond) 1985:94:365-436.

25 Gay NJ. The theory of measles elimination: implications for the design of elimination strategies. J Infect Dis 2004;189(S1):S27-35.
26 Health Protection Report. Measles outbreak in the traveller community. http://www.hpa.org.uk/hpr/ archives/2007/news2007/news2107.htm (accessed 23 July 2013).

27 Choi YH, Gay N, Fraser G, et al. The potential for measles transmission in England. BMC Public Health 2008;8:338.

28 Chief Medical Officer. MMR catch-up programme CEM/CMO/2008/12. PL CMO (2008)5. London: Department of Health, 2008.

29 COI and Department of Health. Childhood Immunisation Tracking: Parents of 0-4s. http:// webarchive.nationalarchives.gov.uk/ 20120503082851/http://www.dh.gov.uk/ prod_consum_dh/groups/dh_digitalassets/@dh/@en/ documents/digitalasset/dh_126438.pdf (accessed 23 July 2013).

30 Health Protection Agency. Quarterly vaccination coverage statistics for children aged up to five years in the UK (COVER programme): October to December 2012. http://www.hpa.org.uk/hpr/archives/2013/ hpr1213 cover.pdf (accessed 23 July 2013).

31 Health Protection Report. Confirmed measles cases in England and Wales: update to end-April 2011. http://www.hpa.org.uk/hpr/archives/2011/hpr2111. pdf (accessed 23 July 2013)

32 lacobucci $\mathrm{G}$. Wales sets up drop-in vaccination clinics to tackle measles outbreak. BMJ 2013;346:f2452.

33 Wise J. Largest group of children affected by measles outbreak in Wales is 10-18 year olds. BMJ 2013;346:f2545.

34 WHO 2007. Manual for the laboratory diagnosis of measles and rubella virus infection. 2nd edn. The Department of Immunization, Vaccines and Biologicals, WHO/IVB/07.01. http://www.who.int/ immunization_monitoring/LabManualFinal.pdf

35 http://www.rcpch.ac.uk/news/rcpch-respondsmeaslesoutbreak (accessed 23 July 2013). 